\title{
Flexor Carpi Radialis
}

National Cancer Institute

\section{Source}

National Cancer Institute. Flexor Carpi Radialis. NCI Thesaurus. Code C53155.

A muscle in the forearm running from the head of the humerus to the radial side of the wrist that flexes and radially abducts the hand. 